NASA-CR-204573

\title{
First estimates of the radiative forcing of aerosols generated from biomass burning using satellite data
}

\author{
Sundar A. Christopher, Donna V. Kliche, Joyce Chou, and Ronald M. Welch \\ Institute of Atmospheric Sciences, South Dakota School of Mines and Technology, Rapid City
}

\begin{abstract}
Collocated measurements from the Advanced Very High Resolution Radiometer (AVHRR) and the Earth Radiation Budget Experiment (ERBE) scanner are used to examine the radiative forcing of atmospheric acrosols generated from biomass burning for 13 images in South America. Using the AVHRR. Local Arca Coverage (LAC) data, a new technique based on a combination of spectral and textural measures is developed for detecting these acrosols. Then, the instantaneous shortwave, longwave, and net radiative forcing values are computed from the ERBE instantaneous scanner data. Results for the selected samples from 13 images show that the mean instantaneous net radiative forcing for areas with heavy aerosol loading is about $-36 \mathrm{~W} / \mathrm{m}^{2}$ and that for the optically thin aerosols are about $-16 \mathrm{~W} / \mathrm{m}^{2}$. These results, although preliminary, provide the first estimates of radiative forcing of atmospheric aerosols from biomass burning using satcllite data.
\end{abstract}

\section{Introduction}

Atmospheric aerosol particles, both natural and anthropogenic, are important to the Earth's radiative balance. They scatter the incoming solar radiation and modify the shortwave reflective properties of clouds by acting as cloud condensation nuclei $(\mathrm{CCN})$. Although it has been recognized that aerosols exert a net cooling influence on climate [Twomev et al., 1984; Charlson et al., 1992a,b; Kiehl and Briegleb, 1993, Penmer et al., 1994], this effect has received much less attention than the radiative forcings due to greenhouse gases and clouds. The radiative forcing due to aerosols is comparable in magnitude to current anthropogenic greenhouse gas forcing but opposite in sign [Houghton et al., [990]. One contributing factor for the inability of the current climate models to accurately estimate surface temperatures may be due to the inaccurate characterization of aerosol effects. In order to obtain accurate estimates of aerosol perturbations on the Earth's radiation balance, it is imperative to include the influence of aerosols in climate models. This will enable us to predict realistic global estimates of aerosol radiative effects more conlidently.

Biomass buming, which is widely prevalent in the tropics, serves to clear land for shifting cultivation and the expanding population. It produces large amounts of trace gases and aerosol particles, which play a pivotal role in tropospheric chemistry and climate [Crutzen and Andreae, 1990; Fishman, 1991]. Aerosol particles emitted from biomass burning are a major source of cloud condensation nuclei [Radke, 1989] which affect the microphysics of boundary layer clouds [Kaufman and Nakajima, 1993] and alter the radiation budget of the Earth by increasing the albedo /Coakley el al., 1987; Twomev et al., 1984; Radke et al., 1989 |. Recently, Penner el al. 11992] proposed that smoke particles from biomass burning may have a significant impact on cli-

Copyright 1996 by the American Geophysical Union.

Paper number 96JD02161.

0148-0227/96/96JD-02161\$09.00 mate by altering the global radiation balance. These particles reflect solar radiation back to space directly and also increase the reflectivity of clouds by acting as $\mathrm{CCN}$. They estimate that 114 Tg of smoke is produced per year in the tropics through biomass burning. The smoke also has about the same distribution of particle sizes as do the sulfate aerosols and with comparable lifetimes in the atmosphere. The direct effect of the aerosols generated from biomass burning, combined with the indirect effect of increasing cloud albedo through the aerosol effects on cloud properties, could potentially offset the predicted $\mathrm{CO}_{2}$ induced warming [Penner et al., 1992; Charlson et al., 1991]. Results from NASA's Transport and Atmospheric Chemistry near the Equatorial Atlantic (TRACE $A$ ) experiment also suggests a net cooling effect due to aerosols generated from biomass burning [Anderson et al., 1995]. Most of the studies mentioned above estimate the radiative impact of aerosols by using some form of the radiative transfer equation. This study utilizes the ERBE measurements to estimate the top of the atmosphere (TOA) perturbations produced due to biomass burning.

In this paper, the direct radiative effects of smoke produced through biomass burning are examined using satellite data. The Advanced Very High Resolution Radiometer (AVHRR) Local Area Coverage (LAC) imagery, along with the instantaneous scanner Earth Radiation Budget Experiment (ERBE) data onboard the NOAA 9 platform, are used to examine the radiative effects of biomass burning over Rondonia province in Brazil. The change in the top of the atmosphere (TOA) shortwave (SW) and longwave (L,W) fluxes due to the smoke produced from biomass buming is examined.

The data sets used in this study are reviewed in section 2, and the methodology is explained in section 3 . The results are discussed in section 4 , and section 5 concludes the paper.

\section{Data}

In this study, data from two sensors from the same satellite are used. The NOA 9 AVHRR L $\triangle \mathrm{C}$ data, at a nominal spatial resolution of $1.1 \mathrm{~km}$, is used to detect fires and smoke by using a combination of spectral and textural measures. 'The AVHRR 
instrument has five channels which provides data in the visible, near-infrared and infrared part of the electromagnetic spectrum [Kidwell et al., 1991]. Channel 1 is between 0.58 and $0.68 \mu \mathrm{m}$, channel 2 is between 0.725 and $1.1 \mu \mathrm{m}$, channel 3 is between 3.55 and $3.93 \mu \mathrm{m}$, channel 4 is between 10.3 and $11.3 \mu \mathrm{m}$, and channel 5 is between 11.5 and $12.5 \mu \mathrm{m}$. The instantaneous ERBE scanner data onboard the same satellite at a nominal spatial resolution of about $40 \mathrm{~km}$ is used to examine the TOA SW and LW tluxes due to the smoke produced from biomass buming. The ERBE scanner measures SW radiances between 0.25 and 4 $\mu \mathrm{m}$, longwave radiances between 4 and $50 \mu \mathrm{m}$ and total radiances between 0.25 and $50 \mu \mathrm{m} \mid$ Kopia, 1986|. The ERBE radiances are then converted to TOA fluxes [Barkstrom et al., 1986] using angular dependence models [Suttes et al., 1988, 1989]. The ERBE scanner data onboard the NOAA 9 satellite was opcrational from February 1985 and January 1987. Therefore, collocated analysis between AVHRR and ERBE can only be performed for two biomass burning seasons.

Several preprocessing steps are performed to ensure the quality of the data. The AVHRR data are navigated using an accurate navigation software [Rosborongh et al., 1994] and are calibrated using Kidwell [1991]. Nonlinear calibration of the thermal channels are performed using Weinreb et al. [1990], and the degradations in channels 1 and 2 are estimated using Rao and Chen [1994].

In this study, 25 images (Y.J. Kaufman, personal communication, 1993) during the August 1987, biomass buming season over South America, from NOAA 9, were used to develop a new detection scheme based on spectral and textural measures. Unfortunately, the ERBE scanner onboard NOAA 9 was not operational during that time. Thirteen images from August 13, 1985, to September 5, 1985, were used to further improve the detection scheme and to examine the radiative impact of biomass buming. The area of study is between $55 \mathrm{~W}$ and $75 \mathrm{~W}$ longitude and between $2 \mathrm{~S}$ to $15 \mathrm{~S}$ latitude and is shown in Figure 1. This area had a substantial increase in the rate of deforestation from 1984 to 1986 [Malingreau and Tucker, 1988; Skole and Tucker, 1993] and has been the subject of many investigations [e.g., Salati and Vose, 1983; Nelson and Holben, 1986; Tucker et al., 1984; Prins and Menzel, 1992].

\section{Methodology}

\subsection{Detection of Smoke Generated \\ From Biomass Burning}

In order to examine the radiative impact of smoke generated due to biomass burning, smoke must first be identified in remote sensing imagery. Most detection schemes from satellite imagery rely on a dark uniform background such as water [Rao et al., 1989] or dense vegetation [Kayfman et al, 1990] in order to detect aerosols. But a large contribution of aerosols generated from dust storms, forest fires, and biomass burning are found over land with variable surface albedos. The variable albedo of the background makes the detection of aerosols over land a difficult problem. In this study, a new teclinique based on a combination of spectral and textural measures is used. Several spectral combinations which help identify the aerosols are tirst examined. For example, the ratio of AVHRR channels 1 and 2 is useful for detecting aerosols over water [Rao et al., 1989], and the difference between channels 3 and 4 [Ackerman, 1989] is used to visually examine the separation between the aerosols and the underlying background. Other combinations that were exam-

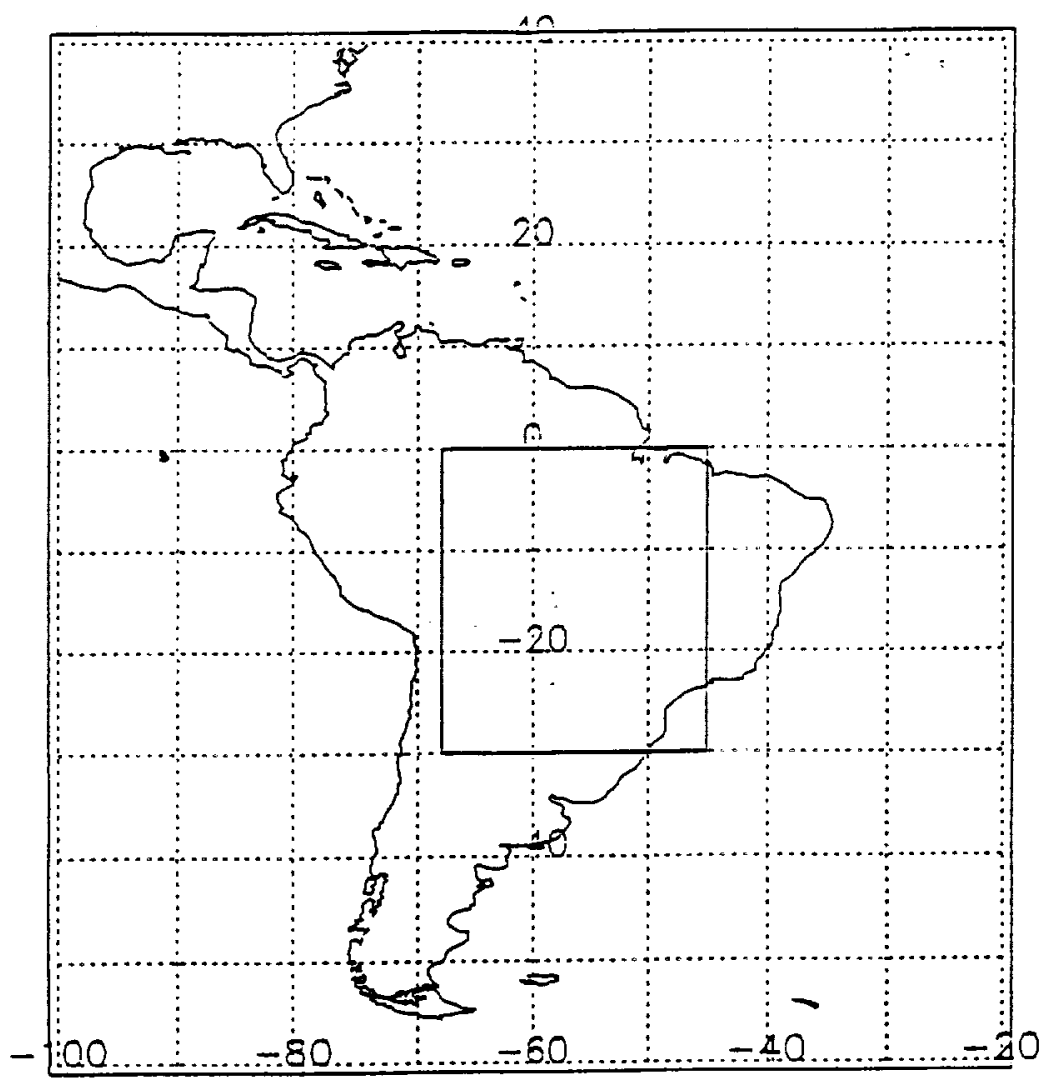

Figure 1. Map of South America with region of study. 
ined include $(1-4) /(1+4),(1-2),(1-2) /(1+2),(4-5)$, and (3$4) /(3+4)$. The spectral combinations that provided the best visual separation between the aerosols and the underlying background then were used to compute the textures. The combination that provided the best results was the $A$ VHRR normalized difference channel combination of $(1-4) /(1+4)$.

Texture analysis plays a prominent role in digital image processing and remote sensing applications. For example, textural information is used for surface feature identification [Hsu, 1978; Marceau et al., 1990], for polar scene identification [Ebert, 1987; Welch et al., 1990, 1992] and for cloud classification [Kuo et al., 1988; Welch et al., 1990, 1992]. Texture is often interpreted in the literature as a set of statistical measures of the spatial distributions of gray levels in the image. In short, textures utilize the spatial information that is available from satellite imagery. In this study, the Gray Level Difference vector (GLDV) approach is used to compute several textural features. This method is computationally efficient and provides a good compromise between accuracy, computer storage, and computer processing time [Key, 1990].

The GLDV method assumes that the textural information in an image is contained in the overall spatial relationship the gray levels in the image have to one another. GLDV is based upon the absolute difference between pairs of gray levels $i$ and $j$ found at a distance $d$ apart, at angle $\phi$ with a fixed direction. The difference vector probability density function $P(m)_{d, \phi}$ is defined for $m=|i-j|$, where $i$ and $j$ are the corresponding gray levels, and is obtained by dividing the gray level frequencies of occurrence by the total frequencies. From the density function, the following individual textural measures are computed:

Contrast

$$
C O N_{d, \phi}=\sum_{m} m^{2} P(m)_{d, \phi}
$$

Local Homogeneity

$$
H O M_{d, \phi}=\sum_{m}^{n} P(m)_{d, \phi} /\left(I+m^{2}\right)
$$

Mean

$$
M E A N_{d, \phi}=\sum_{m} m P(m)_{d, \phi}
$$

Angular Second Moment

$$
A S M_{d, \phi}=\sum_{m} P(m)_{d, \phi}^{2}
$$

Entropy

$$
E N T R O_{\alpha, \phi}=-\sum_{m} P(m)_{d, \phi} \log P(m)_{d, \phi}
$$

Difference Cluster Shade

$$
S H A D E_{d \phi}=\sum_{m}\left(m-\mu_{d \phi}\right)^{3} P(m)_{d, \phi} / \sigma^{\frac{3}{2}}
$$

$$
\begin{gathered}
\text { where } \mu_{d, \phi}=\sum_{m} m P(m)_{d, \phi} \\
\sigma=\sum_{m}\left(m-\mu_{d \phi}\right) P(m)_{d, \phi}
\end{gathered}
$$

Difference Cluster Prominence

$$
\operatorname{PROM}_{d, \phi}=\sum_{m}(m-\mu)^{4} P(m)_{d, \phi} / \sigma^{2}-3
$$

Contrast provides a measure of the degree of spread in gray levels; angular second moment is a measure of the homogeneity in the scene; entropy represents a measure of disorder in the scene; local homogeneity is a measure of the amount of local similarity in the scene; difference cluster shade is a measure of the degree to which the outliers in the histogram favor one side or another of the mean; and difference cluster prominence measures the effect of the outliers on the peak of the distribution.

A $9 \times 9$ pixel window then was used to compute the textural features for each pixel. Therefore, for each textural feature, a corresponding textural image was created. These images then were examined to determine the best possible visual separation between the aerosols and the underlying background. The textural feature that provided the best combination was the "mean".

Plate 1 shows an example of an AVHRR three-band overlay of one image over the Rondonia province from Sept. 3, 1985. The size of the image is approximately $3.7 \times 10^{5} \mathrm{~km}^{2}$. The red color displays channel 1 , blue displays the "mean" textural measure of AVHRR channel combination $(1-4)(1+4)$, and green displays channel $(1-4) /(1+4)$. Fires are denoted in red. (The fire detection scheme is discussed in section 3.2). For this particular image, 4459 fires were detected. The white boxes denote selected collocated ERBE footprints (see section 3.3). Several interesting features can be noted from this image. Several smoke plumes (labelled A-D) can be seen, with dense smoke plume (labelled E) toward the middle of the image. These dense smoke plumes often are 4-6 kms in height above the surface (E. Browell, personal communication, 1995). The light yellow color in Plate 1 represents hazy conditions due to smoke being transported away from the source. These haze layers associated with biomass burning often extend hundreds of kilometers [Andreae et al., 1988] and are widely prevalent during the biomass burning season in the Amazonia basin. Plate 1 shows that there is a good separation between the background and the diffuse smoke. The background appears dark in this image, the diffuse smoke is light yellow, the dense smoke is tan, and water clouds appear as blue. Using spectral measures alone, it was not possible to produce an equally good separation between these features. It is noted that while the AVHRR channel ratio of $(1-4) /(1+4)$ is sensitive to both clouds and smoke, it is the combination of the spectral and textural features which provides the best visual separation among the smoke, clouds, and the underlying background.

\subsection{Fire Detection}

The AVHRR LAC imagery has been used to detect fires due to biomass burning over South America [Matson and Holben, 1987; Kaufman et al., 1990; Malingreau and Tucker, 1988; Prins and Menzel, 1992], Africa [Kennedy et al., 1994; Cahoon et al., 


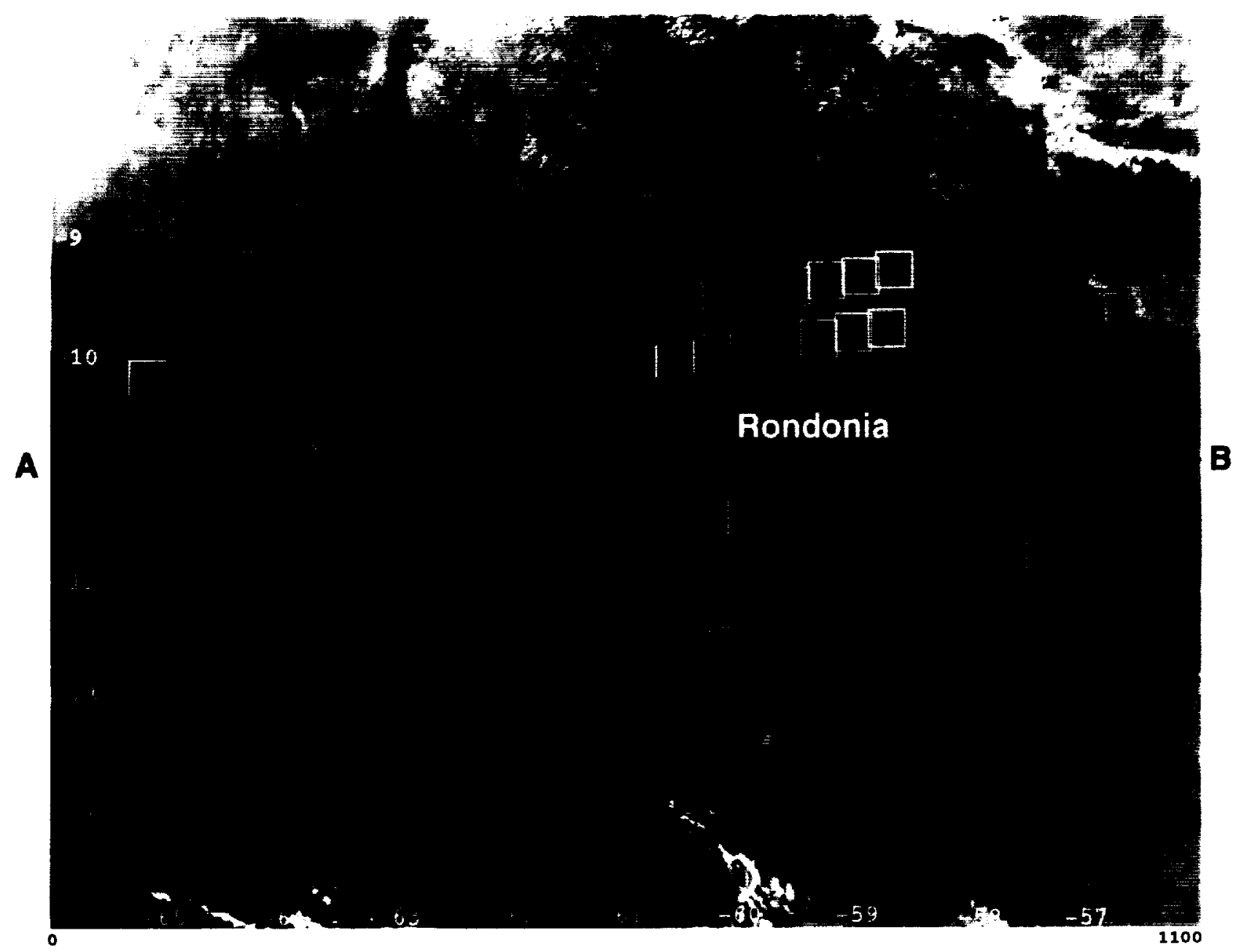

Plate 1. AVHRR three-band overlay of one image over Rondonia province, Brazil from September 3, 1985 (Red, channel 1; Green, Channel $[(1-4)(1+4)]$; Blue, MEAN $[(1-4)(1+4)]$. Fires displayed in red and white boxes represent selected collocated ERBE footprints. In this image land appears dark, dense smoke as tan, haze as light yellow, and water clouds as blue.

1992] and southeast Asia [Malingrean, 1986]. Although subpixel scale fires can be missed [Robinson, 1991], the AVHRR LAC data has provided important information on the number of fires and their spatial extent. In this study, fires were detected following the method of Kaufman et al. [1990]. A fire was detected if the AVHRR channels 3 and 4 satisfied the following criteria: (1) $\mathrm{T} 3 \geq 316 \mathrm{~K}$; (2) $\mathrm{T} 3 \geq \mathrm{T} 4+10 \mathrm{~K}$; and (3) $\mathrm{T} 4>250 \mathrm{~K}$.

The first condition ensures that the channel 3 temperatures are close to the saturation level. The second condition ensures that dry grass and hot bare soils are not classified as fire pixels, and the third condition ensures that strongly reflective clouds are not being included. Figure $2 \mathrm{a}$ shows the channel 3 and channel 4 temperatures for the transect shown in Plate 1. The channel 3 temperatures over the fires are larger than channel 4 temperatures by about 10 to $30 \mathrm{~K}$, which makes the detection of fires possible. Figure $2 b$ shows the difference between channel 3 and channel 4 temperatures for the same transect. For pixel values between 350 and 400 , the difference in temperatures between channel 3 and channel 4 is greater than $10 \mathrm{~K}$.

\subsection{Collocation of AVHRR With ERBE Data}

In order to determine the radiative impact of aerosols generated from biomass burning, narrowband AVHRR LAC data is collocated with the broadband measurements from the ERBE scanner. The ERBE scanner onboard NOAA 9 operated from February 1985 to January 1987. During this time, the instrument provided valuable information on the radiation budget of the earth-atmosphere system. By combining the narrowband AVHRR radiometer with the broadband ERBE scanner on the same platform, we can more accurately investigate the radiative impact of aerosols.

The scanner onboard NOAA 9 measures the broadband shortwave, longwave, and total radiances. The ERBE radiances are then inverted to TOA lluxes [Barkstrom et al., 1989] using a Maximum Likelihood Estimation (MLE) method [Wielicki and Green, 1989; Diekmann and Smith, 1989]. In this procedure, the geotype of a pixel is a static procedure. It depends upon the measured area and a predetermined atlas of geotype. The surface is classified into (1) ocean, (2) land, (3) snow, (4) desert, and (5) coastal categories. The clouds are classified into (1) partly cloudy, (2) mostly cloudy, and (3) overcast categories. As pointed out by Ackerman and Chung [1992] the geographical regions with aerosols tend to be misclassified as being partly cloudy or mostly cloudy, thereby resulting in errors in TOA fluxes. Diekmanm and Smith [1989] and Li and Leighton [1991] provide estimates of the errors by assuming the inappropriate limb darkening and bidirectional models. Diekmann and Smith [1989] 

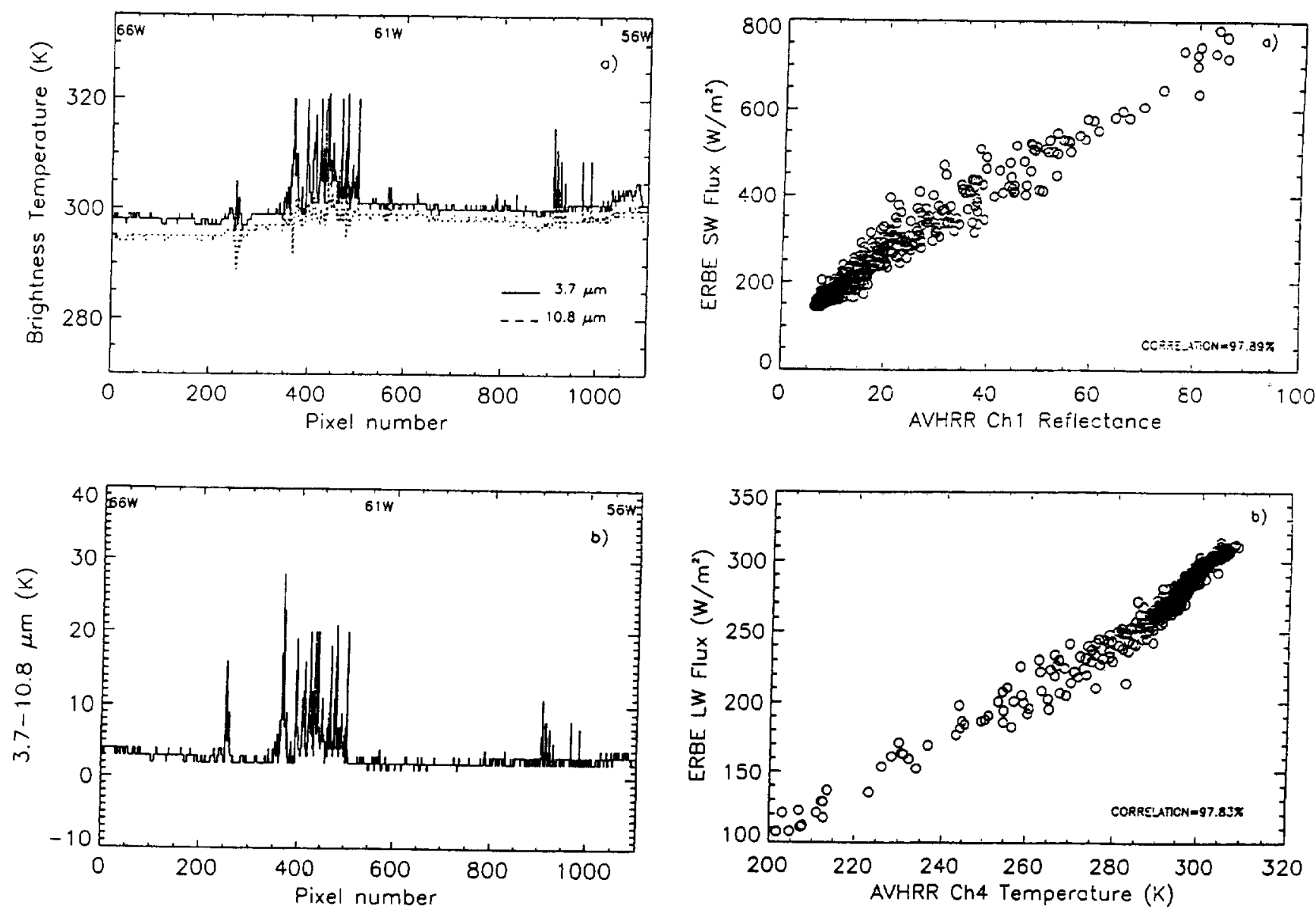

Figure 2. West to east cross section through the area studied in Rondonia province (transect shown in Plate 1: (a) brightness temperature in channels 3 and 4; (b) brightness temperature of the difference between channels 3 and 4 .

show that the errors in LW flux estimates are negligible for all scene types and that the maximum errors in SW flux estimates are about $14 \%$. Until realistic limb darkening and bidirectional models are developed for aerosols, the ERBE measurements will provide the only direct method for estimating the radiative impact of aerosols.

The collocation procedure follows that of $L i$ and Leighton [1991] but is modified for AVHRR LAC imagery. First, the center of an AVHRR pixel that corresponds to an ERBE pixel is identified. The distance between the centers are usually less than $2 \mathrm{~km}$. If this distance is greater than $5 \mathrm{~km}$, the pixel is flagged and is not used. The group of $37 \times 37$ pixels is assumed to correspond to one ERBE pixel. Then the ERBE shortwave flux is correlated with the AVIRR channel 1 reflectance and the ERBE longwave flux is correlated with the AVHRR channel 4 temperature. Correlation coefficients are usually greater than $95 \%$. Figures $3 \mathrm{a}$ and $3 \mathrm{~b}$ show the correlation for the aforementioned parameters. The correlation coefficient is $98 \%$ in this case. Correlation coefficients of $98 \%$ ensure that the data have been properly calibrated, navigated, and collocated.

\section{Results}

The results are divided into two sections. First, the TOA fluxes due to biomass burning is discussed, and then second, the radiative forcing is examined.

Figure 3. AVHRR and ERBE collocation: (a) ERBE shortwave (SW) flux versus channel 1 reflectance, correlation equals $97.89 \%$; (b)'ERBE longwave (LW) flux versus channel 4 temperature, correlation equals $97.83 \%$.

\subsection{Top of Atmosphere (TOA) Fluxes Due to Biomass Burning}

There have been very few attempts to study the regional radiative impact of aerosols produced due to biomass burning using satellite data. One of the reasons is the difficulty in separating the aerosols from the underlying background; also, AVHRR LAC imagery has been expensive and difficult to obtain. Ackerman and Chung [1992] used AVHRR and ERBE data to study the radiative effects of dust storms on the TOA radiative energy budget. Their study showed that the aerosols from dust storms reduced the TOA SW fluxes over oceans by as much as $40-90 \mathrm{~W} / \mathrm{m}^{2}$. The change in $\mathrm{SW}$ and $\mathrm{LW}$ fluxes due to aerosols over land was $5-20 \mathrm{~W} / \mathrm{m}^{2}$ and $20-50 \mathrm{~W} / \mathrm{m}^{2}$, respectively, as compared to clear sky values. They note that it is often difficult to separate the effects of dust over land due to the similar reflective characteristics of the underlying background.

In this study, the combination of spectral and textural measures is used in separating the aerosols produced due to biomass burning over land. Even the optically thin aerosol features can be identified. Figure 4 shows the relationship between ERBE SW flux versus $L W$ flux for selected samples of land, haze, and dense smoke extracted from Plate 1. These samples were identified by visual examination of the image. The SW flux values are between $140 \mathrm{~W} / \mathrm{m}^{2}$ and $200 \mathrm{~W} / \mathrm{m}^{2}$, and the $\mathrm{LW}$ flux values are between 280 and $300 \mathrm{~W} / \mathrm{m}^{2}$. The land samples are well- 


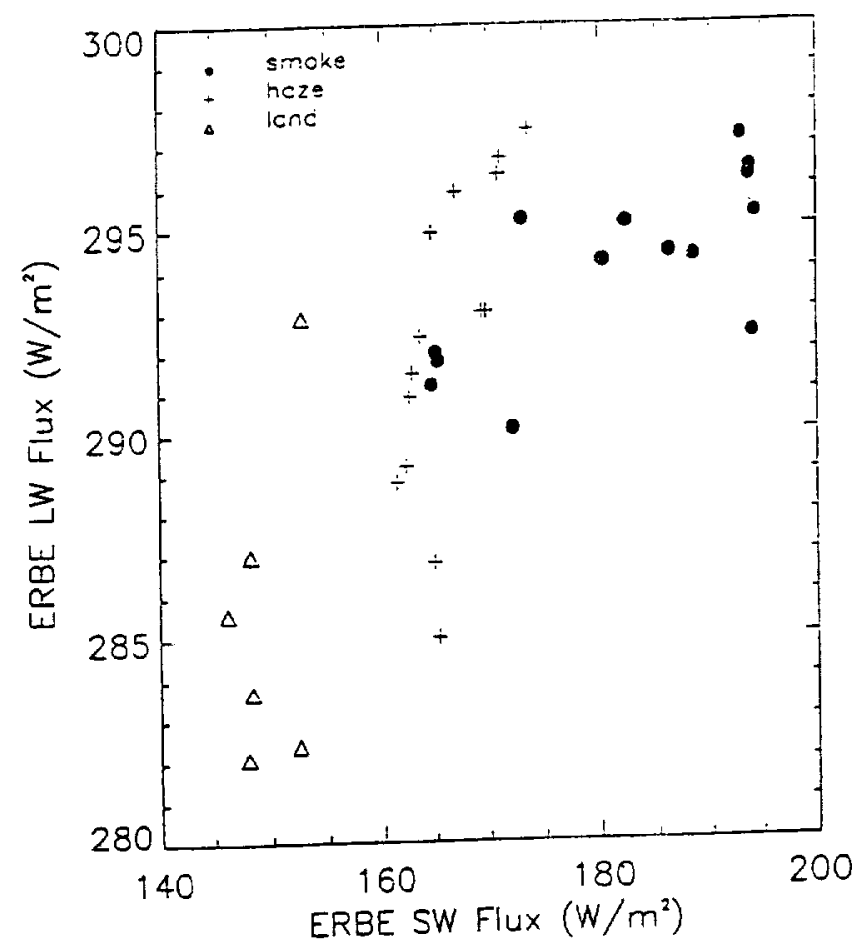

Figure 4. SW versus I.W ERBE fluxes for selected samples of land, haze, and dense smoke extracted from Plate 1.

clustered together, with average SW flux values of about 150 $\mathrm{W} / \mathrm{m}^{2}$ and LW flux values of about $290 \mathrm{~W} / \mathrm{m}^{2}$. The SW flux values of haze and dense smoke are higher than the underlying background by about $30-50 \mathrm{~W} / \mathrm{m}^{2}$. The dense smoke has $\mathrm{LW}$ flux values higher than that of clear land by about $10-15 \mathrm{~W} / \mathrm{m}^{2}$ because most of the dense smoke is found directly above the fires. On the other hand, some haze samples have LW flux values similar to that of land, while others have I.W flux values similar to that of the dense smoke values. The difference beween SW tlux values over land and the dense smoke is about $30-60 \mathrm{~W} / \mathrm{m}^{2}$, whereas the change in LW flux between clear land and dense smoke is about $10-20 \mathrm{~W} / \mathrm{m}^{2}$. For all of the images used in this study, the LW flux values of dense smoke were larger than that of clear land, whereas the diffuse smoke, which had spread to several hundreds of miles and which included no fire pixels, usually had LW flux values similar to that of bare land. On the other hand, the SW flux values for both the dense and diffuse smoke was higher than that of land. Note that the solar zenith ranged between $37^{\circ}$ and $44^{\circ}$ for this image.

Figure 5 shows the histogram of AVHRR channel 3 and channel 4 temperatures for (a) land, (b) dense smoke, and (c) haze for one selected collocated ERBE footprint. Figure 5a shows that for the land sample, the peak channel 4 temperatures are between 295 and $296 \mathrm{~K}$ and the channel 3 temperatures are between 298 and $299 \mathrm{~K}$. Figure $5 \mathrm{~b}$ shows the histogram for a dense smoke sample with 247 fires. The channel 3 temperatures are much larger than the channel 4 temperatures, making the detection of fires from AVHRR data possible. All of the dense smoke samples had fires below them. Figure 5c shows the channel 3 and channel 4 temperatures for one selected "haze" sample. These optically thin aerosols are transported hundreds of kilometers away from their source and, therefore, have no fires directly below them. Therefore, the channel 3 temperatures are much smaller than those of the dense smoke samples.

\subsection{Radiative Forcing of Aerosols Generated From Biomass Burning}

In order to quantify the effect of aerosols on the regional radiative energy budget, two terms are defined which are (1) shortwave acrosol radiative forcing (SWARF) and (2) longwave acrosol radiative forcing (LWARF). SWARF is defined as: $\mathrm{SWARF}=\mathrm{S}_{0}\left(\alpha_{c t r}-\alpha_{a e r}\right) ;$ and $\mathrm{LWARF}=\mathrm{LW}_{\text {cir }}-\mathrm{LW}_{\text {aer }}$, where $\mathrm{S}_{0}$ is incoming solar flux, $\alpha$ is albedo, and $\mathrm{LW}$ is longwave flux. The subscripts clr and aer denote clear sky and aerosol conditions. Note that the radiative forcing defined in this manner is termed "instantaneous forcing" because no space or time averaging has been performed

To assess the radiative impact of aerosols, selected collocated samples from the $\triangle$ VIIRR and ERBE data are utilized. These samples were selected by visual examination of the 13 $\Lambda$ VIHRR images the two main classes of interest are (1) dense smoke and (2) the optically thin aerosol haze. The dense smoke plumes are often found directly over the fires and the haze often extends hundreds of kilometers during the biomass burning season. The mean shortwave and longwave forcings of dense smoke was found to be $-46.8 \mathrm{~W} / \mathrm{m}^{2}$ and $9.9 \mathrm{~W} / \mathrm{m}^{2}$, respectively. The mean SW forcing of the optically-thin aerosol haze was -25.9 $\mathrm{W} / \mathrm{m}^{2}$, and the mean $\mathrm{LW}$ forcing was $8.9 \mathrm{~W} / \mathrm{m}^{2}$. The net forcing of dense smoke was, therefore, $-36.9 \mathrm{~W} / \mathrm{m}^{2}$, and the net forcing of the optically thin aerosol haze was $-16.9 \mathrm{~W} / \mathrm{m}^{2}$. These results indicate that the instantaneous net radiative forcing of aerosols is one of cooling. While obtaining samples for this analysis, care was taken to ensure that the collocated pixel was more than $75 \%$ filled with either dense smoke or haze

While the selection of samples is a useful exercise for obtaining first estimates of the radiative forcing, the task is tedious and time consuming. An automated fire and smoke detection scheme currently is being explored [Berendes et al., 1996]. The radiative forcing ol dense smoke as a function of the number of fires below the collocated sample is investigated using a set of simple thresholds. Figure 6a and $6 \mathrm{~b}$ show the the TOA SW and LW flux for four classes: (1) clear land, (2) 1-20 fires, (3) 21-50 fires, and (4) $>50$ fires. The category $1-20$ fires means that if a collocated sample had $1-20$ fires and if the mean temperature of the collocated sample was warmer than $250 \mathrm{~K}$, the TOA SW and LW flux from the ERBE: scanner was noted. The threshold of $250 \mathrm{~K}$ eliminates pixels with cold clouds. One of the drawbacks of this method is the classification of low bright clouds as dense smoke. However, a visual examination of several images over the Amazonian area reveals that collocated pixels with fires often have dense smoke plumes as opposed to bright water clouds. Results from the recently held SCAR-B experiment in Brazil also support this assumption (M. King, personal communication, 1995). Figure 6a shows that the TOA SW flux increases as the number of fires within a collocated pixel increases. Thirteen images over the Rondonia province were used to create this figure. Clear land regions with no fires have an average SW flux of $165 \mathrm{~W} / \mathrm{m}^{2}$. Figure $6 \mathrm{~b}$ shows the corresponding $\mathrm{LW}$ flux values for the four classes. Clear sky LW flux values are around 310 $\mathrm{W} / \mathrm{m}^{2}$. The $\mathrm{LW}$ llux values are not well separated when compared to the SW llux values. The category 1-20 fires have smaller L,W flux values when compared to the $21-50$ and $>50$ fire categories.

Table 1 shows the instantaneous shortwave, longwave, and net forcing for these three classes. As the number of fires increase, the shortwave aerosol forcing (SWARF) values also increase. Collocated ERBBE pixels with 1-20 fires have an average 

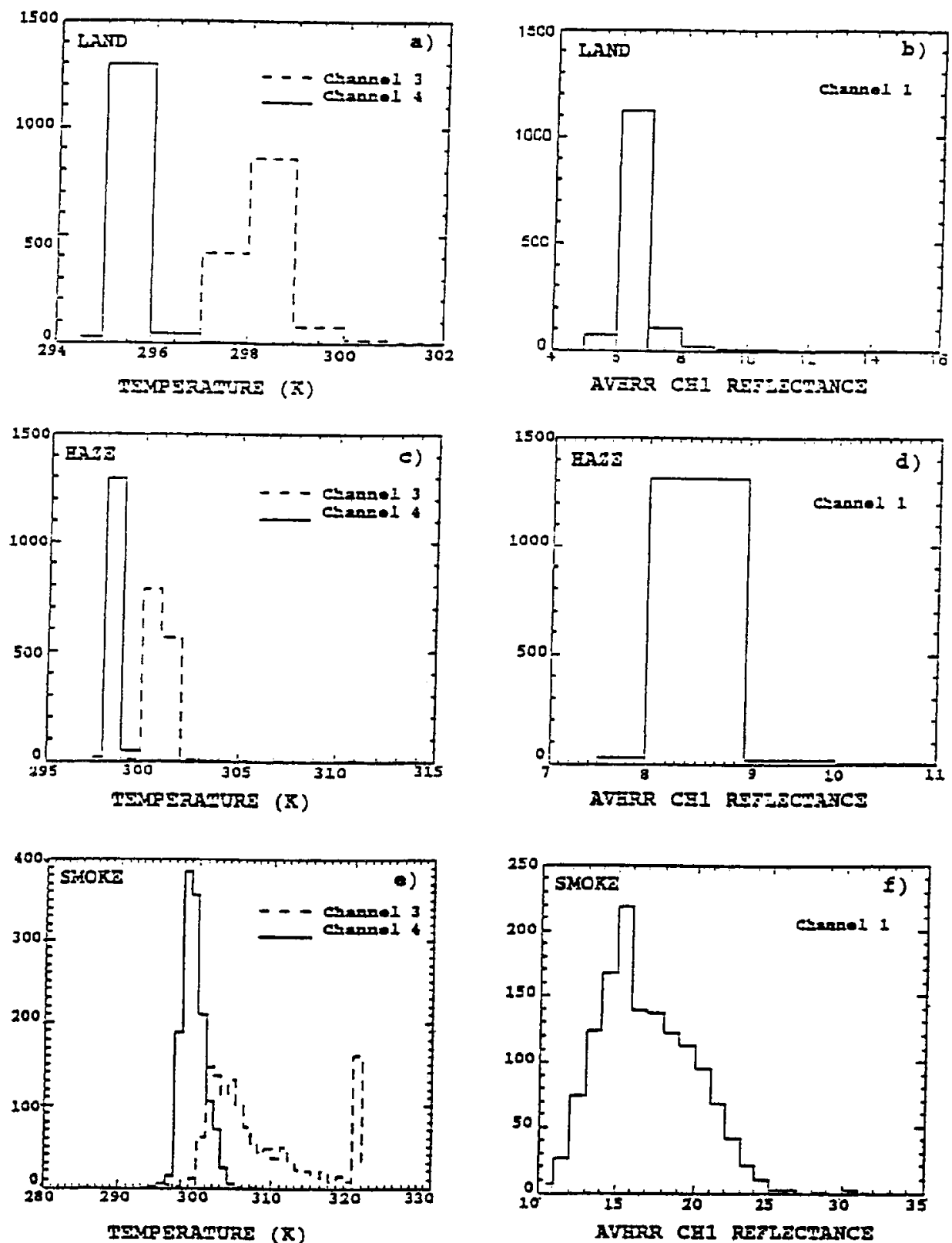

Figure 5. Histograms of channels 3, 4, and 1, representative for land, dense smoke, and haze samples: (a) land, channel 3 and 4 temperature; (b) land, chainel 1 reflectance; (c) haze, channel 3 and 4 temperature; (d) haze, channel 1 reflectance; (e) dense smoke, channel 3 and 4 temperature; (f) dense smoke, channel 1 reflectance.

SWARF value of about $13.4 \mathrm{~W} / \mathrm{m}^{2}$, and this value increases to about $-28.8 \mathrm{~W} / \mathrm{m}^{2}$ as the number of fires increase beyond 50 . This shows the shortwave reflective properties of dense smoke is well correlated with the number of fires below them. On the other hand, the relation between longwave aerosol forcing (LWARF) and the number of fires is not apparent. The net forcing for the categories 21-50 fires and >50 fires shows a negative net radiative forcing, whereas the 1-20 tires shows a slightly positive net forcing value

\section{Conclusions}

An approach to study the radiative effects of aerosols generated from biomass burning has been developed. $A$ new smoke detection scheme based on a combination of textural and spectral measures shows that it is possible to separate even the optically thin acrosols from the underlying background. Collocated measurements from the ERBE scanner have been used to examine the direct radiative effects of these aerosols. This study provides the first observational estimates of the radiative effects of aerosols generated from biomass burning using satellite data. Results show that the "mean" textural measure, along with the spectral combination of AVIIRR channels $(1-4) /(1+4)$ and channel 1 , provides a good visual separation between the aerosols and the underlying background. Collocated measurements from AVIRR and ERBE show that the mean instantaneous net radiative forcing of dense smoke is $-36 \mathrm{~W} / \mathrm{m}^{2}$ and that of the optically thin smoke is about $-16 \mathrm{~W} / \mathrm{m}^{2}$. The shortwave radiative forcing of 

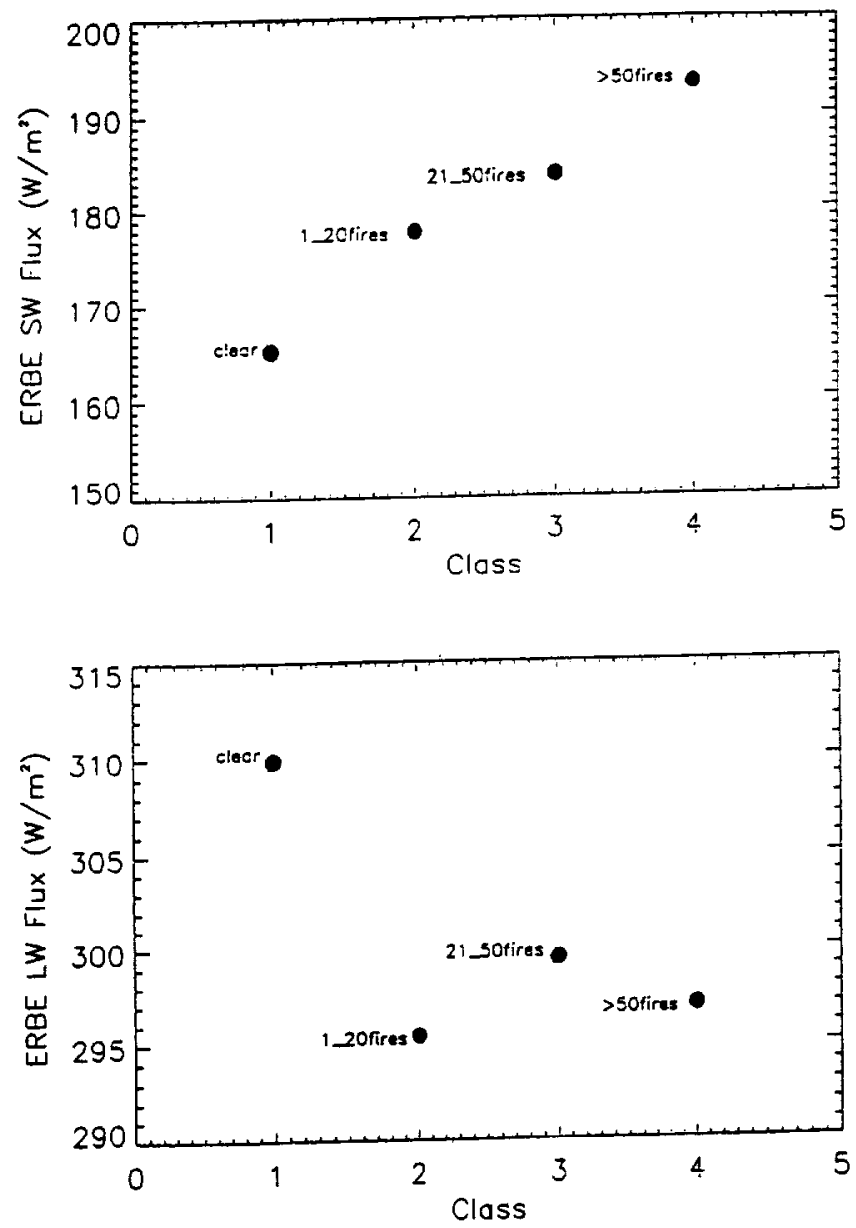

Figure 6. Unsupervised classification based on the number of lires detected in the $37 \times 37$ footprint for four classes: (1) clear land, (2) 1-20 fires, (3) 2l-50 fires, and (4) more than 50 fires; (a) ERBE SW flux; (b) ERBE LW flux

dense smoke increases as the number of fires increase, where as the longwave forcing shows no such dependence. These results from 13 selected images show that the direct instantaneous net radiative forcing of aerosols generated from biomass burning is onc of "cooling". These results support the radiative transfer modelling work of Penner et al. [1992] and [Anderson et al., 1995]

Finally, it is noted that this is the beginning of an effort to understand the regional radiative effects of aerosols using satellite data. Future work will focus on examining the radiative forcing of aerosols as a function of major ecosystems and characterizing the radiative effects as a function of optical properties.

Table 1. Radiative forcing of smoke as a number of fires

\begin{tabular}{lrrr}
\hline \multicolumn{1}{c}{ Class } & $\begin{array}{c}\text { SW Forcing, } \\
\text { W/m }\end{array}$ & $\begin{array}{c}\text { LW Forcing, } \\
\text { W/m }\end{array}$ & Net Forcing, W/m \\
\hline $1-20$ fires & -13.3 & 14.6841 & 1.31410 \\
$21-50$ fires & -19.3 & 10.5859 & -8.75366 \\
$>50$ fires & -28.8 & 13.1785 & -15.6584 \\
\hline
\end{tabular}

$\mathrm{LW}$ is longwave and $\mathrm{SW}$ is shortwave.
Acknowledgments. This research was supported under NASA grant NAGW-3740 managed by Robert Curran. Special thanks to Dan Baldwin for the navigation software, the Langley DAAC for the ERBE data, and to Bill Wojcik for his programming help. Appreciation is extended to Connie Crandall for typing this manuscript. The authors also thank the anonymous reviewers for their comments.

\section{References}

Ackerman. S. A., Using the radiative temperatures difference at 3.7 and 11 $\mu \mathrm{m}$ to track dust outbreaks, Remote Sensing Environ., 27, 129-133, 1989.

Ackerman, S. A., and H. Chung, Radiative effects of airborne dust on regional energy budgets at the top of the atmosphere, J. Appl. Meteorol., 31, 223-233, 1992 .

Anderson, B. E., W. B. Grant, G. L. Gregory, E. V. Browell, J. E. Collins, Jr., G. W. Sachse, D. R. Bagwell, C. H. Hudgins, D. R. Blake, and N. J. Blake, Aerosols from biomass burning over the south tropical Allantic region: Distributions and impacts, J. Geophys. Res., in press, 1995.

Andreae, M. O., E. V. Browell, M. Garstang, G. L. Gregory, R. C. Hariss, G.F. Hill, and D. J. Jacob, Biomass burning and associated haze layers over South Amazonia, J. Geophys. Res., 93, 1509-1527, 1988.

Barkstrom, B. R., and G. L. Smith, The Earth Radiation Budget Experiment: Science and implementation, Rev. Geophys., 24, 379-390, 1986.

Barkstrom, B. R., E. Harrison, G. Smith, R. Green, J. Kebler, R. Cess, and the ERBE Science Team, Earth Radiation Budget Experiment (ERBE) archival and April 1985 results, Bull. Am. Meteorol. Soc.. 70. 12541262,1989

Berendes, T. A., A Pretre, R. C. Weger, D. V. Vulcan, and R. M. Welch, 1996: A paired-histogram rule-base approach for cloud and smoke classification applied to polar and desert regions and South America. Submitted to JGR-Atmos.

Cahoon, D. C. Ir., B. J. Stocks, J. S. Levine, W. R. Coffer III, and K. P. ONeill, Seasonal distribution of African Savanna fires, Nature, 359, $812-815,1992$.

Charlson, R. J., J. 1 angner, H. Rodhe. C. B. Leovy, and S. G. Warren, Perturbation of the northern hemisphere radiative balance by backscattering from anthropogenic sulfate aerosols, Tellus. 43AB, 152-163, 1991.

Charlson. R. I. S E. Schwartz, J. M. Hales. R. D. Cess, J. A Coakley, Jr., J. E. Hansen, and D. J. Hofmann, Climate forcing by anthropogenic aerosols. Science. 255, 423-430, 1992a.

Charlson, R. J., S. I. Schwartz, J. M. Ilales, R. D. Cess, J. A. Coakley, Jr., J. E. Hansen, and D. I. Hofmann. Aerosols and global warning, Science, $256,598-599,1992 \mathrm{~b}$.

Coakley, J. A., R. L. Bernstein, and P. A. Durkee, Effect of ship-stack eflluents on cloud reflectivity, Science, 237, 1020-1022, 1987.

Crutzen, P. J., and M. O. Andreae, Biomass burning in the tropics: Impact on atmospheric chemistry and biogeochemical cycles, Science, 250, $1669-1678,1990$

Diekmann, F. 3., and G. L. Smith, Investigation of scene identification algorithms for radiation budget measurements, J. Geophys. Res. 94. 3395$3412,1989$.

Ebert, E., A patten recognition technique for distinguishing surface and cloud types in the polar regions. J. Clim. Appl. Meteorol., 26. 1412$1427,1987$.

Fishman, J., Probing plentary pollution from space, Environ. Sa. Technol. $25,613-620,1991$

Hougiton, J. T., G. J Jenkins, and J. J. Ephraums (eds.), Climate Change. The IPCC Sctentific Assessment, 362 pp.. Cambridge Univ. Press, New York, 1990.

Hsu, S-Y, Texture - tone analysis for automated land-use mapping, Photogram. Eng. Rem. Sens., 44, 1393-1404, 1978.

Kaufman. Y. J.. and T. Nakajima, Effect of Amazon smoke on cloud microphysics and alhedo-analysis from satellite imagery, J. Appl. Meteorol., 32, 729-744, 1993

Kaufman, Y. J.. C. J. Tucker, and I. Fung, Remote sensing of biomass burning in the tropies. J. Geophys. Res. 9S, 9927.9939, 1990.

Kennedy, P. J.. A. S. Belward, and J-M. Giregoire. An improved approach to fire monitoring in West Africa using AVHRR data, Int. J. Remote Sens., $15(11), 2235-2255,1994$.

Key 1 . Cloud cover inalysis with Arctic AVHRR data, 2, Classification with spectral and textural measures, J. Geophys. Res., 95, 7661-7675, 1990.

Kidwell, K. B. NOAA Polar Orbiter Data Users Guide. Dept of Comm. NOANNESDIS, Washington, D.C., 1991. 
Kiehl, J. T., and B. P. Briegleb. The relative roles of sulfate aerosols and greenhouse gases in climate forcing, Science. 260,311-314, 1993.

Kopia, L. P., Earth radiation budget experiment scanner instrument, Rev. Geophys., 24, 400-406, 1986.

Kuo, K. S., R. M. Welch, and S. K. Sengupta, Structural and textural characteristics of cirrus clouds observed using high spatial resolution LANDSAT imagery, J. Appl. Meteorol., 27, 1242-1260, 1988.

$\mathrm{Li}, \mathrm{Z}$, and H. G. Leighton, Scene identification and its effect on cloud radiative forcing in the Arctic. J. Geophys. Res., 96, 9175-9188, 1991.

Malingreau, J. D., Global vegetation dynamics: Satellite observations over Asia, Int. J. Remote Sens., 7 (9), 1121-1146, 1986.

Malingreau, J. D., and C. J. Tucker, Large scale deforestation in the southeastern Amazon Basin of Brazil, Ambio, 17, 49-55, 1988.

Marceau, D. J., P. J. Howarth, J. M. Dubois, and D. J. Gratton. Evaluation of the grey-level cooccurrence matrix method for land-cover classification using SPOT imagery, IEEE Trans. Geosci. Rem. Sens., 28, 513-519, 1990.

Matson, M., and B. Holben, Satellite detection of tropical burning in Brazil, Int. J. Remote Sens., 8 (3), 509-516, 1987.

Nelson, R., and B. Holben, Identifying deforestation in Brazil using multiresolution satellite data, Int. J. Remore Sens., 7(3), 429-448, 1986.

Penner J. E., et al., Quantifying and minimizing uncertainty of climate forcing by anthropogenic aerosols. Bull. Am. Meteorol. Soc., 75, 375-400, 1994.

Penner, J. E., R. E. Dickinson, and C. A. O'Neill, Effects of aerosols from biomass buming on the global radiation budget, Science, 256, 1432$1434,1992$.

Prins, E. M., and W. P. Menzel, Creostationary satellite detection of biomass burning in South America. Int. J. Remote Sens., /3(15), 2783-2799, 1992.

Radke, L.F., Airbonce observations of cloud microphysics modified by anthropogenic forcing, paper presented at Symposium on Atmospheric Chemistry and Global Climate, Amer. Meteorol. Soc., Anaheim, Calif., Jan. 29 - Feb. 3, 1989.

Radke, L. F., J. A. Coakley, Jr., and M. D. King, Direct and remote sensing observations of the effects of ships on clouds, Science, 246, 1146-1149, 1989.

Rao, C.R.N.. and J. Chen, Post-launch calibration of the visible and nearinfrered channels of the Advanced Very High Resolution Radiometer on NOAA 7, 9, 11 spacecraft. NOAA Tech. Rep. NISDIS78, 22 pp., Natl. Ocean. Atmos. Admin., Silver Spring, MD, 1994.

Rao, C.R.N., L.L. Stowe, and E.P. McClain, Remote sensing of aerosols over oceans using AVHRR data: Theory, practice and applications, Int. J. Remote Sens., JO. 743-749, 1989.
Robinson. J. M. Fire from space: Global fire evaluation using infrared remote sensing. Int. J. Remole. Sens. 12 (1). 3-14. 1991

Rosborough. G. W., D. G. Baldwin, and W. I. Emery, Precise AVHRR image navigation. IEHE Trans. Geosci. Rem. Sens., 32(3), 644-657, 1994.

Salati, E., and P. B. Vose, Depletion of tropical rain forests, Ambio. 12 (2), $67.71,1983$

Skole, D., and C. I. Tucker. Tropical deforestation and habitat fragmentation in the Amazon: Satellite data from 1978 to 1988, Science, 260, 1905. $1910,1993$.

Suttles, J. T., R. N. Green, P. Minnis, G. L. Smith, W. F. Staylor, B. A. Wielicki, 1. J. Walker, D. F. Young, V. R. Taylor, and L. L. Stowe, Angular radiation models for earth-atmosphere system, in Shortwave Radiation, vol. I, 147 pp., NASA Ref. Publ., 1184, 1988.

Suttles, J. T.. R. N. Green. G. I. Smith. B. A. Wielicki, I. J. Walker, V. R. Taylor, and I. I.. Stowe. Angular Radiation Models for Earth-Atmosphere System. vol. II. Longwave Radiation, NASA Ref. Pub., 1184, 1989.

Tucker, C. 1., B. N. Holhen. and T. E. Groff, Intensive forest clearing in Rondonia, Brazil, as detected by satellite remote sensing, Remore Sens. Environ., 15, 255-261, 1984.

Twomey, S. A., M. Piepgrass, and T. L. Wolfe, An assessment of the impact of pollution on global albedo, Tellits. 36B, 356-366, 1984.

Weinreb, M. P., G. Hamilton, S. Brown, and R. J. Koczor, Nonlinearity corrections in calibration of advanced very high resolution radiometer in. frared channels, J. Geophys. Res.. 95 (C5), 7381-7388, 1990.

Welch, R. M., K. S. Kuo, and S. K. Sengupta, Cloud and surface textural features in polar regions, IEEE Trans. Geosci. and Remote Sens., 28, $520-528,1990$.

Welch, R. M., S. K. Sengupta, A. K. Goroch, P. Rabindra, N. Rangaraj, and M. S. Navar, Polar cloud and surface classification using AVHRR imagery: An intercomparison of methods, J. Appl. Meteorol., 31, 405-420, 1992.

Wielicki, B. A., and R. N. Green, Cloud identification for ERBE radiative flux retrieval, J. Appl. Meteorol., 28, 1133-1146, 1989.

J. Chou, S.A. Christopher, D.V. Kliche, and R.M. Welch, Institute of Atmospheric Sciences, South Dakota School of Mines and Technology, 501 E. St. Joseph Street, Rapid City, SD 57701-3995.

(e-mail:chou@cloud.ias.sdsmt.edu; sundar@cloud.ias.sdsmt.edu; donna@cloud.ias.sdsmt.edu; welch@cloud.ias.sdsmt.edu)

(Received November 17, 1995; revised June 5, 1996; accepted June 25,1996 .) 
